\title{
A Sustainable Agriculture Production Model of Pampanga State Agricultural University in Central Luzon, Philippines
}

\author{
Norman De Jesus ${ }^{1}$, Honorio Soriano $\mathrm{Jr}^{1}$, Rafael Rafael ${ }^{2}$, Emmanuel Pangilinan ${ }^{3}$, Cesar Orpiada ${ }^{3}$, Estrella Zabala ${ }^{4}$, \\ Regina Loria ${ }^{5}$, Ernesto Supan ${ }^{1}$, Filomena Reyes ${ }^{1}$, Celso Reyes ${ }^{1}$ and Angelina De Jesus ${ }^{1}$ \\ 1. College of Agriculture Systems and Technology (CAST), Pampanga State Agricultural University (PSAU), Magalang, Pampanga \\ 2011, Philippines \\ 2. College of Arts and Sciences (CAS), Pampanga State Agricultural University, Magalang, Pampanga 2011, Philippines \\ 3. Alternative Low-Input Agriculture Systems (ALIAS) Center, Pampanga State Agricultural University, Magalang, Pampanga 2011, \\ Philippines
}

4. College of Home Economics and Food Sciences (CHEFS), Pampanga State Agricultural University, Magalang, Pampanga 2011, Philippines

5. College of Education (COEd), Pampanga State Agricultural University, Magalang, Pampanga 2011, Philippines

\begin{abstract}
Alternative Low-Input Agriculture Systems (ALIAS) center advocates organic and sustainable food production system through farm/field demonstration and piloting. The center undertakes activities, including research and development, extension and training, technology dissemination, linkaging and promotional activities. The study established a campus-based demonstration technology showcasing ALIAS to facilitate easy technology diffusion. The objectives of this research were to promote: (1) bio-fertilizers and plant-based pesticides in managing insect pests and diseases of organic vegetables and fruit crops; (2) lotus-tilapia integration as a new modality of farming system in frequently flooded areas; (3) honeybee as pollinators to enhance productivity of organic vegetable and fruit crops; (4) Adlai as intercrop to organic vegetable and fruit crops in support to rice sufficiency; (5) native chicken-coffee integration. The results show that: (1) microbial inoculants and plant-based pesticides are effective in controlling diseases and insect pest, respectively; (2) lotus integration in tilapia production system have no negative effect on the tilapia yield; (3) honeybees as pollinators enhances fruit setting by $42 \%-68 \%$ in different crops; (4) Adlai is a viable intercrop for organic vegetable and fruit crops; (5) native chicken integration was found to be beneficial in terms of soil fertility, insect pest control, natural weeding practices and cultivation in the coffee plantation.
\end{abstract}

Key words: Organic agriculture, bio-fertilizer, plant-based pesticides, honeybee integration, techno-demonstration.

\section{Introduction}

The continuous use and overuse of chemical fertilizers create an imbalance in the nutrient composition of the soil, which makes the soil acidic and hence reduces the soil productivity. The soaring price of these fertilizers is likewise an alarming concern among farmers. Not to mention, the health hazard poses to humans heavily by the crops applied

Corresponding author: Norman De Jesus, Ph.D., research field: organic agriculture. with the said synthetic fertilizer materials. The concerned government departments and private sector alike are now pursuing ways and means to adopt organic farming. Production from organic farming is healthy and highly palatable. Moreover, the increasing cost of chemical fertilizer has increased farm production inputs/costs. The use of organic fertilizer will substantially lower the production cost of agricultural produce.

In support of Republic Act 10068, an act providing 
for the development and promotion of organic agriculture in the Philippines, the Pampanga State Agricultural University (PSAU), through its Alternative Low-Input Agriculture Systems (ALIAS) center, promotes organic and sustainable production systems through farm demonstrations and piloting. In the province of Pampanga in the island of Luzon, organic farmers obtained their knowledge through training and seminars [1]. In Central Luzon, organic production systems have low utilization and adoption. Most of the constraint in the promotion of organic agriculture in the region can be solved through an integrated production systems program [2]. Various organic production system techno-demo in the university will help hasten the promotion of organic agriculture in the region. The objectives of this ALIAS center research program were to demonstrate the complementary effects of crops and livestock integration in enhancing farm productivity and to generate substantial income for the university to support sustainable research and development activities. The objectives of this research were to promote bio-fertilizers and plant-based pesticides utilization, lotus-tilapia integration, honeybee integration, Adlai integration and native chicken-coffee integration.

\section{Materials and Methods}

Exploratory research was done to determine the advantages, limitations and challenges of the different production systems. The research was broken down by production system as follows: (1) bio-fertilizers and plant-based pesticides; (2) lotus-tilapia integration; (3) honeybee as pollinators; (4) Adlai as intercrop to organic vegetable and fruit crops; (5) native chicken-coffee integration.

2.1 Bio-fertilizers and Plant-Based Pesticides in Managing the Insect Pests and Diseases of Organic Vegetables and Fruit Crops

The first component of the project showcased how to utilize various types of bio-fertilizers (bio-fertilizer compost, liquid bio-fertilizer, organic foliar fertilizer) and beneficial microorganisms in the production of organic vegetables. The aim was to demonstrate the technology that we can produce yields comparable or better than that of conventional farming systems without using any synthetic chemicals. Different types of plant extracts with bioactive components, such as neem, kakawate, marigold and microbial inoculants were used in the prevention of diseases and protection against different types of pests. The goal was to demonstrate alternative ways of controlling pests and diseases without relying on hazardous synthetic chemicals.

2.2 Lotus-Tilapia Integration as a New Modality of Farming System in Frequently Flooded Areas

The project relates to increasing number of farms frequently flooded due to climate change. The potential of integrating lotus into tilapia farming system was undertaken to enhance the productivity of tilapia growers as a potent mitigating measure. A fish pond in the center where tilapia is grown was planted with lotus. The tilapia yield was recorded to determine the effect of lotus integration in tilapia farming system.

\subsection{Honeybee as Pollinators to Enhance Productivity of Organic Vegetable and Fruit Crops}

To enhance the productivity of organic vegetable and fruit crops, beekeeping was introduced as pollinators to organic vegetable and fruit crops. Bee colonies were placed at strategic locations at the different production areas of ALIAS center. The bee colonies were placed at the sweet tamarind, cashew, squash, cucumber and tomato production areas. Percent fruit set of the crops pollinated by honeybees were recorded and compared with those with honeybees.

\subsection{Adlai as Intercrop to Organic Vegetable and Fruit Crops in Support to Rice Sufficiency}

Adlai seeds were planted in the field of existing 


\section{A Sustainable Agriculture Production Model of Pampanga State Agricultural University in Central Luzon, Philippines}

organic vegetables and fruit orchards of PSAU, in between squash, okra, eggplant, pole sitao and tomato, also in between mango trees, tamarind trees and in between coffee plants. Individual and combined yield performance and profitability of these said crops were determined and analyzed following the analysis of variance. The standard cultural management for both crops was followed, that is, nutrient management, insects and diseases management done organically. Organic fertilizer with 5 ton/ha was basally applied before Adlai seeds were drilled. Goat manure tea and vermicompost tea were sprayed every $15 \mathrm{~d}$ until flowering. Adlai grains were also used to feed native chickens and developed various food and non-food products.

\subsection{Native Chicken-Coffee Integration}

Native chickens were raised under coffee plantation to showcase the positive effects of their integration and complementation to enhance productivity. The daily weight gain, egg hatchability and chick mortality were recorded. The effect on the coffee trees was also observed.

\subsection{Training and Extension Activities}

The center continuously conducts hands-on training and orientation to various stakeholders about organic production systems. Furthermore, to enhance promotion and dissemination, the following were also undertaken: media interviews, poster and leaflets production, participation to conferences and exhibits, among many others. The number of clienteles who benefited from the project from 2010 to 2013 was tallied. The income generated by the project was also computed.

\section{Results and Discussion}

3.1 Bio-fertilizers and Plant-Based Pesticides in Managing the Insect Pests and Diseases of Organic Vegetables and Fruit Crops

Soil microorganisms play important roles in controlling plant diseases, eliminating plant pests and converting nutrients into more available form for plants. It was found out, during the various technology demonstrations, the difference of using bio-fertilizers and microbial inoculums using single strain microorganism and multi-strains. It was imperative to use multi-strains to achieve the desired microbial fertilizer efficiency. The single strain was lacking in terms of fertilizer efficiency. This was observed from the efficiency of using effective microorganisms compared to just using Lactobacillus spp. and Trichoderma spp.. Most microbial inoculants used as effective microorganism production are bacteria [3]. They can not tolerate high temperature and dry conditions. They can not be stored for a long time and only used in liquid form. Spore forming microorganisms, like Trichoderma, are easily stored, transported and applied in dust or granule form. These limitations in using various microorganisms in crop production should be considered to achieve the desired result in using them.

The microbial inoculation approach often needs a long time to work and may not meet the plant's need in time. Mixing the microbial inoculants to the bio-fertilizer, both in solid and liquid form produces a quick-acting and long-term acting organic fertilizer. Plant-based pesticides rely on the bioactive components found in the plant parts, such as alkaloids and tannins that can be utilized to improve plant health and protection from the pest. Preparation of plant-based pesticides can be done by various means, such as extraction, expression as well as by fermentation. The latter was the preparation of choice in the various technology applications at ALIAS due to the synergistic effect of both using plant bioactive components and beneficial microorganisms. Plant-based pesticides were developed to prevent insect infestations. Different plant preparations were developed for different types of insects. The concentration of the bioactive component of the plant is the main factor that affects the efficiency of 
plant-based pesticides.

Beneficial microorganism plays an important role in the control and prevention of plant diseases [4]. The various mechanisms of disease control and plant protection were tested, such as microbe-microbe interaction (Trichoderma versus fungi), plant-microbe interaction (Trichoderma in roots, leaves, etc.) and metabolite produced (lactic acid by Lactobacillus spp.). Trichoderma, due to its hyperparasitic nature, can be used as biological control of plant fungi [5]. During seed germination and plant growth, they become intimately associated with developing the root-rhizosphere ecosystem, which leads to improving growth and protects the roots system from diseases [6]. Lactobacillus spp. produced lactic acid, which is an anti-microbial compound. Lactobacillus inoculums and effective microorganisms can be sprayed on plants to prevent bacterial diseases.

\subsection{Lotus-Tilapia Integration}

The growth parameter of tilapia harvested from ponds with lotus plants was found at par with those raised without lotus. This implied the positive integration effect of the two. On the study of Yi et al. [7], lotus co-cultured with tilapia is an effective way of recycling nutrients in the pond and an environmentally-sound production system. Noteworthy is the capacity of lotus plants to filter polluted water. Other lotus-based food products and non-food products were developed and ready for commercialization as well.

\subsection{Honeybee as Pollinators to Enhance Productivity of Organic Vegetable and Fruit Crops}

The contribution of honeybees on selected crops as pollinators was measured. Cashew and squash showed $61 \%$ to $68 \%$ dependency to pollinators, while sweet tamarind, cucumber and tomato had $42 \%$ to $45 \%$ dependency (Fig. 1). The production system has mutual benefit between the crop and the honeybee. Organic vegetable and fruit crop production ensure food resources needed to sustain the honeybees as well as other pollinators [8]. It can be emphasized further that other important products, such as honey, pollen, propolis, beeswax, among others, can be derived. Also, other products, like scented candles, soap, ointment, lip balm, can be processed.

\subsection{Adlai as Intercrop to Organic Vegetable and Fruit} Crops in Support to Rice Sufficiency

Adlai is planted as intercrop to the selected organic vegetable crops and orchards. In both cases, the contribution of Adlai in enhancing the crop productivity was undertaken and measured. Under orchard, Adlai planted between the coffee plants was recorded to have the highest added income amounting to Php21,200/ha. Moreover, those planted between organic squash and organic okra obtained Php19,400/ha and Php18,000/ha, respectively. Adlai as intercrop is a viable sustainable intensification

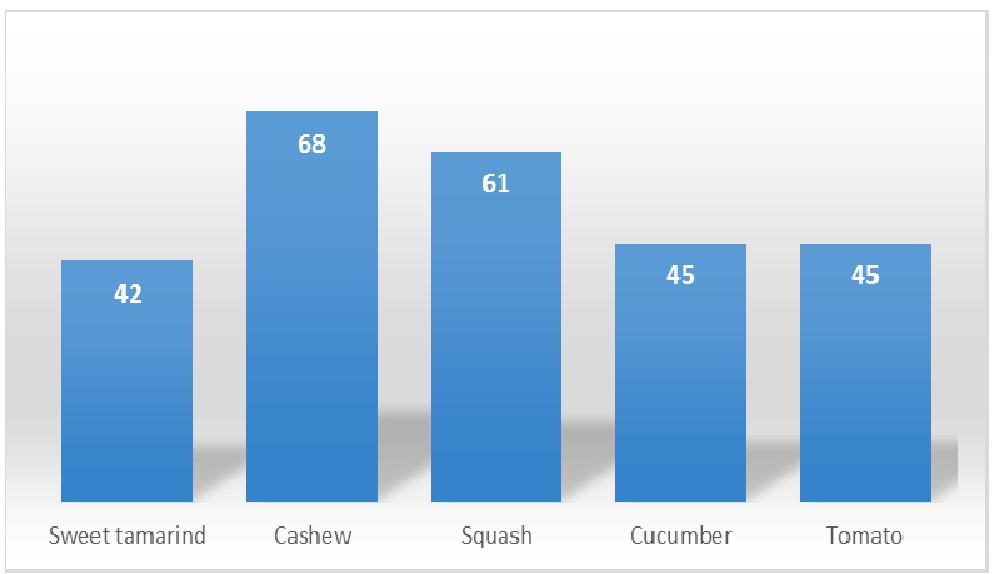

Fig. 1 Percent (\%) fruit set of selected crops pollinated by honeybees. 


\section{A Sustainable Agriculture Production Model of Pampanga State Agricultural University in Central Luzon, Philippines}

practice to support rice sufficiency. Sustainable intensification practices increase productivity and income, conserve soil and water, reduce external inputs, improve agro-ecological processes, such as nutrient and water cycling, boost human nutrition and adapt to climate change [9].

Also, Adlai grain was used as feed to native chickens. It was noted that Adlai grain produced comparable growth effects to native chicken vis-a-vis it regular counterpart, which is corn. Food products were likewise developed from Adlai grains, such as Adlai tinapay, Adlai bilo-bilo, sticky Adlai dumplings and Adlai wine. These are being evaluated for commercialization.

\subsection{Native Chicken-Coffee Integration}

A substantial growth rate of $6.5 \mathrm{~g}$ average daily gain was recorded with a final weight of $1.2 \mathrm{~kg}$ for six months of rearing per native chicken reared under coffee, and it was found to be comparable to a standard parameter on native chicken under backyard raising system. Egg hatchability was recorded at 65\% while the chick mortality during brooding and the hardening period were only 2.5\%. Integrated crop-animal system can be strengthened through increased promotion of organic agriculture in the region [10]. The system of production was found to be more beneficial in terms of soil fertility, insect pest control, natural weeding practices and cultivation. Likewise, a symbiotic relationship was observed for native chicken raised under the coffee trees.

\subsection{Training and Extension Activities}

For the past four years of its operation, the center was able to cater to about 2,696 individuals, who were afforded either of the following extension modalities

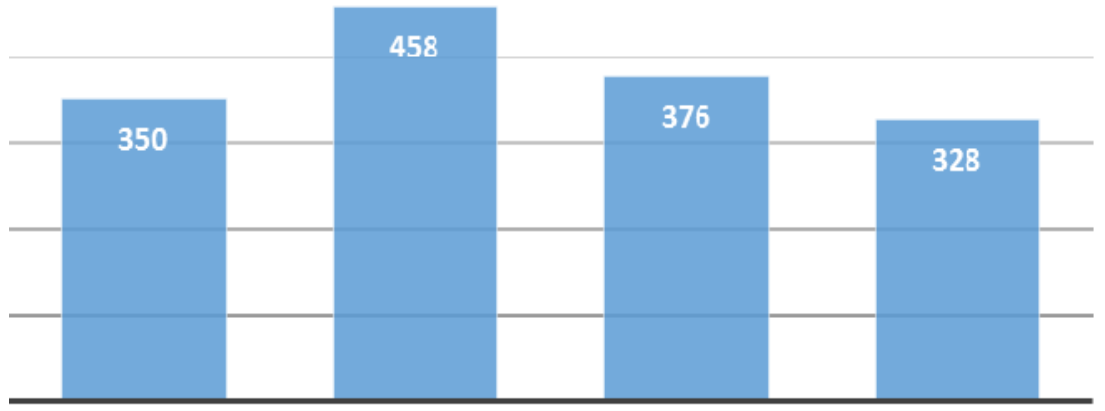

Fig. 2 Number of clientele/beneficiaries who have been benefited from the project from 2010 to 2013.

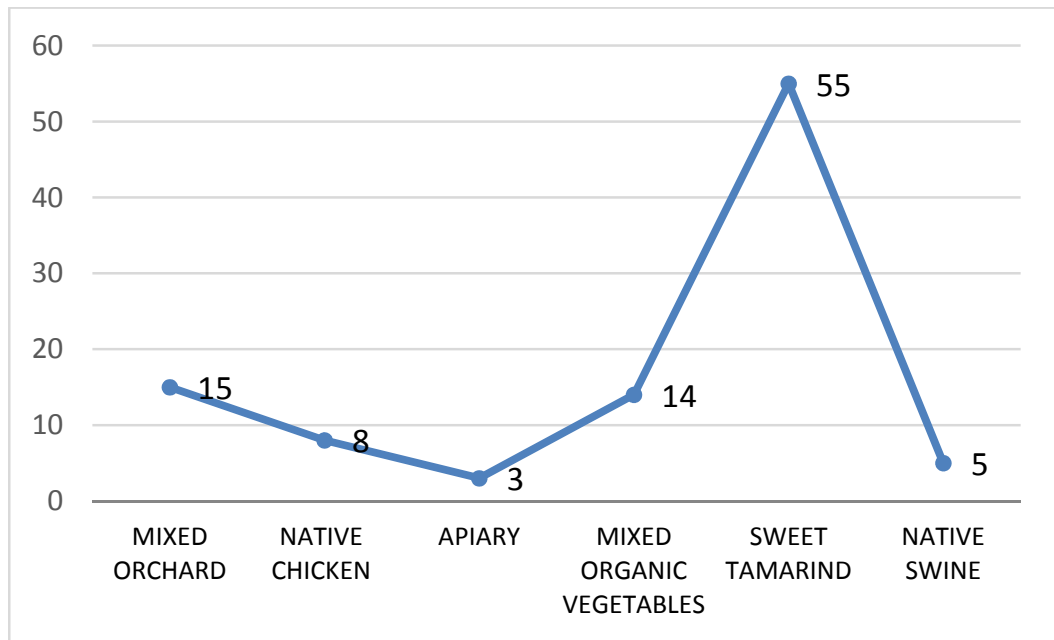

Fig. 3 Distribution of income of the major components of ALIAS center for the year 2013-2014. 
and other related technology transfer, such as training, hands-on demonstration, orientation and seminars, among many others (Fig. 2). The technology afforded to them ranges not only from organic vegetable and fruit crops production systems to product processing and development but also native chicken and pigs as well.

\subsection{Income Generated}

About Php1,451,000 income was generated for the year 2013-2014 for all the research projects under ALIAS center. The top earners are sweet tamarind seedlings and fruits, and the mixed organic vegetable crops pegged at Php801,000 and Php250,000, respectively (Fig. 3). The income generated flows back into funding new research and extension activities in the center.

\section{Conclusions}

Techno-demo of the various organic production systems helps promote the organic agriculture advocacy of the government. The following are lessons learned from the research activities of ALIAS center:

(1) Microbial inoculants and plant-based pesticides are effective in controlling diseases and insect pest, respectively;

(2) Lotus integration in tilapia production system has no negative effect on the tilapia yield;

(3) Honeybees as pollinators enhance fruit setting by $42 \%-68 \%$ in different crops;

(4) Adlai is a viable intercrop for organic vegetable and fruit crops;

(5) Native chicken integration is found to be beneficial in terms of soil fertility, insect pest control, natural weeding practices and cultivation in the coffee plantation.

Besides, there are about 350 to 450 individuals every year who benefit from the various activities of the center. The complementation of each agri-enterprises produces not only an overall enhanced productivity to the farm from various main products and secondary products but also to the health of the soil and environment. Wastes are processed into organic fertilizer through composting with the use earthworms (African nightcrawler) and also fed into biogas digester to produce cooking fuel and ultimately into organic fertilizer.

In between processes, varied products and sub-products are produced. Main products produced are fresh organic vegetables, fresh fruits, fresh eggs and chicken meats, fresh native pig meets, seeds and seedlings, honey, fish, among others. Sub-products are wine, jam, vinegar, tea, bread, ointment, soap, lotion, lip balm and others. The technology behind of such products is even available to be diffused to interested private entrepreneurs. About Php1,451,000 income was generated for the year 2013-2014 for all the components under PSAU-ALIAS center. The top earners are sweet tamarind seedlings and fruits and the mixed organic vegetable crops pegged at Php801,000 and Php250,000, respectively.

\section{References}

[1] De Jesus, N. G., Juico, C. C., and Guinto, R. N. 2011. "Initiatives to Promote Organic Agriculture in the Province of Pampanga, Philippines.” Journal of ISSAAS 17 (1): 247.

[2] Porciuncula, F. L., Galang, L. M., and Parayno, R. S. 2015. "Going Organic: Understanding the Organic Vegetables Production Environment in Central Luzon, Philippines.” Journal of Agricultural Technology 11 (2): 341-66.

[3] Higa, T., and Parr, J. 1994. Beneficial and Effective Microorganisms for a Sustainable Agriculture and Environment. Atami, Japan: International Nature Farming Center.

[4] Diver, S. 2001. "Nature Farming and Effective Microorganisms.” Accessed August 27, 2002. http://ncatark.uark.edu/ steved/Nature-Farm-EM.html.

[5] Harman, G. E., and Kubicek, C. P. 1998. Trichoderma and Gliocladium: Enzymes, Biological Control, and Commercial Applications. Vol. 2. London: Taylor \& Francis, 393.

[6] Weeden, C. R., Shelton, A. M., and Hoffman, M. P. 2008. "Biological Control: A Guide to Natural Enemies in North America.” Accessed March 23, 2007. 


\section{A Sustainable Agriculture Production Model of Pampanga State Agricultural University in Central Luzon, Philippines}

http://www.nysaes.cornell.edu/ent/biocontrol/predators/c oleomeg.html.

[7] Yi, Y., Lin, C. K., and Diana, J. S. 2002. "Recycling Pond Mud Nutrients in Integrated Lotus-Fish Culture.” Aquaculture 212 (1-4): 213-26.

[8] Winfree, R., Williams, N. M., Dushoff, J., and Kremen, C. 2007. "Native Bees Provide Insurance against Ongoing Honey Bee Losses.” Ecology Letters 10 (11): 1105-13.

[9] Ares, A., Thierfelder, C., Reyes, M., Eash, N. S., and Himmelstein, J. 2015. "Global Perspectives on Conservation Agriculture for Small Households.” In
Conservation Agriculture in Subsistence Farming: Case Studies from South Asia and beyond 2015, edited by Chan, C., and Fantle-Lepczyk, J. Wallingford, UK: CABI International, 22-54.

[10] Simarak, S., Loapaiboon, B., Sommart, K., Duangjinda, M., Pattarajinda, V., Lowilai, P., and Phasuk, Y. 2005. "Integrated Crop-Animal Systems in Thailand." In Integrated Crop-Animal Systems in Southeast Asia: Current Status and Prospects, edited by Sombilla, M. A., and Hardy, B. Los Bafios, Philippines: International Rice Research Institute (IRRI), 117-49. 